\title{
Common Eye Diseases and their Management edition 4, (2016) authors: Nicholas R. Galloway, Winfried M. K. Amoaku, Peter H. Galloway, Andrew C. Browning pp. 270 ISBN 978-3-319-32867-6, Springer International Publishing
}

\author{
Robert Borny ${ }^{1}$. Carsten H. Meyer ${ }^{1}$
}

Received: 5 June 2018 / Accepted: 7 June 2018 / Published online: 15 June 2018

(C) Springer-Verlag GmbH Germany, part of Springer Nature 2018

The fourth edition of this textbook provides an introduction to the primary care of eye disease and the specialty of medical and surgical ophthalmology not only for medical students and general practitioners but also for young trainee ophthalmologists, nurses, and optometrists. The need for this primary care readership to be well informed about frequent ocular conditions is obvious and even more important today than when the first edition was published.

Since its first publication of Common Eye Diseases and their Management in 1985, there have been numerous advances in the fields of glaucoma, corneal disease, medical retina, and genetics, making the education of Ophthalmology critical and extremely important. The importance of ocular screening in diabetic eye disease or management of eye conditions in the elderly patients (glaucoma, age-related macular degeneration) has also made it essential for the primary care doctor to have a basic knowledge of eye diseases.

This new edition remains in its original format with four main parts: Introducing the eye, Primary eye care problems, Problems of the eye surgeon, and Problems of the medical ophthalmologist. The authors begin in each chapter a dialog highlighting its aim, followed by a detailed description. The text of each chapter is well written in a structured and colloquial style, providing an excellent introduction to the eye, with clear explanations and problem-oriented approach. It avoids many technical terms and concentrates on eye diseases at a basic level, which are likely seen by general practitioners. This fourth edition is illustrated by additional and improved color clinical photographs, excellent illustrations, and diagrams offering a comprehensive insight into the field of Ophthalmology which helps the reader feel at ease with the text. Most chapters end with an interactive control of the interested readership giving them a number of questions "After reading this section you should be able to answer the following questions". This is an excellent learning aid for anyone searching for a basic introduction to Ophthalmology and remembering the relevant key points.

Significant advances in the diagnosis and management of eye disease made an update of this classic text book necessary. Ophthalmology has gained more subspecialties, and the referring doctor has to know these in order to make appropriate referrals. The authors succeeded with their unchanged format. Enlarged chapters, updated reference list and a new digital version have significantly improved the current knowledge in Ophthalmology at a primary level in this valuable book. Essential for general practitioners as well as medical students, we highly recommend it.

Carsten H. Meyer

meyer_eye@yahoo.com

1 Pallas Clinics, Aarau, Switzerland 